\title{
Complexity of the social environment and behavioural plasticity drive divergent gene expression in the brain of ant queens
}

\author{
Fabio Manfredini ${ }^{1}$, Carlos Martinez-Ruiz ${ }^{2}$, Yannick Wurm ${ }^{2,2}$, DeWayne Shoemaker ${ }^{3}$, and \\ Mark Brown ${ }^{4}$ \\ ${ }^{1}$ University of Aberdeen \\ ${ }^{2}$ Queen Mary University of London \\ ${ }^{3}$ University of Tennessee \\ ${ }^{4}$ Royal Holloway University of London
}

July 31, 2020

\begin{abstract}
Social life and isolation pose a complex suite of challenges to organisms prompting significant changes in neural state. However, plasticity in how brains respond to social challenges remains largely unexplored. The fire ants Solenopsis invicta provide an ideal scenario for examining this. Fire ant queens may found colonies individually or in groups of up to 30 queens. Here, we artificially manipulated availability of nesting sites to test how the brain responds to social vs. solitary colony founding at two key timepoints, and to group size. The difference between group and single founding queens involves only 1 gene when behaviour is still plastic and queens can switch from one modality to another, while hundreds of genes are involved once behaviours are more canalized. Furthermore, we show that large groups lead to greater changes in gene expression than small groups, perhaps due to higher cognitive demands of a more complex social environment.
\end{abstract}

\section{Hosted file}

FM_manuscript_300720_final.pdf available at https://authorea.com/users/347652/articles/ 473272-complexity-of-the-social-environment-and-behavioural-plasticity-drive-divergentgene-expression-in-the-brain-of-ant-queens 

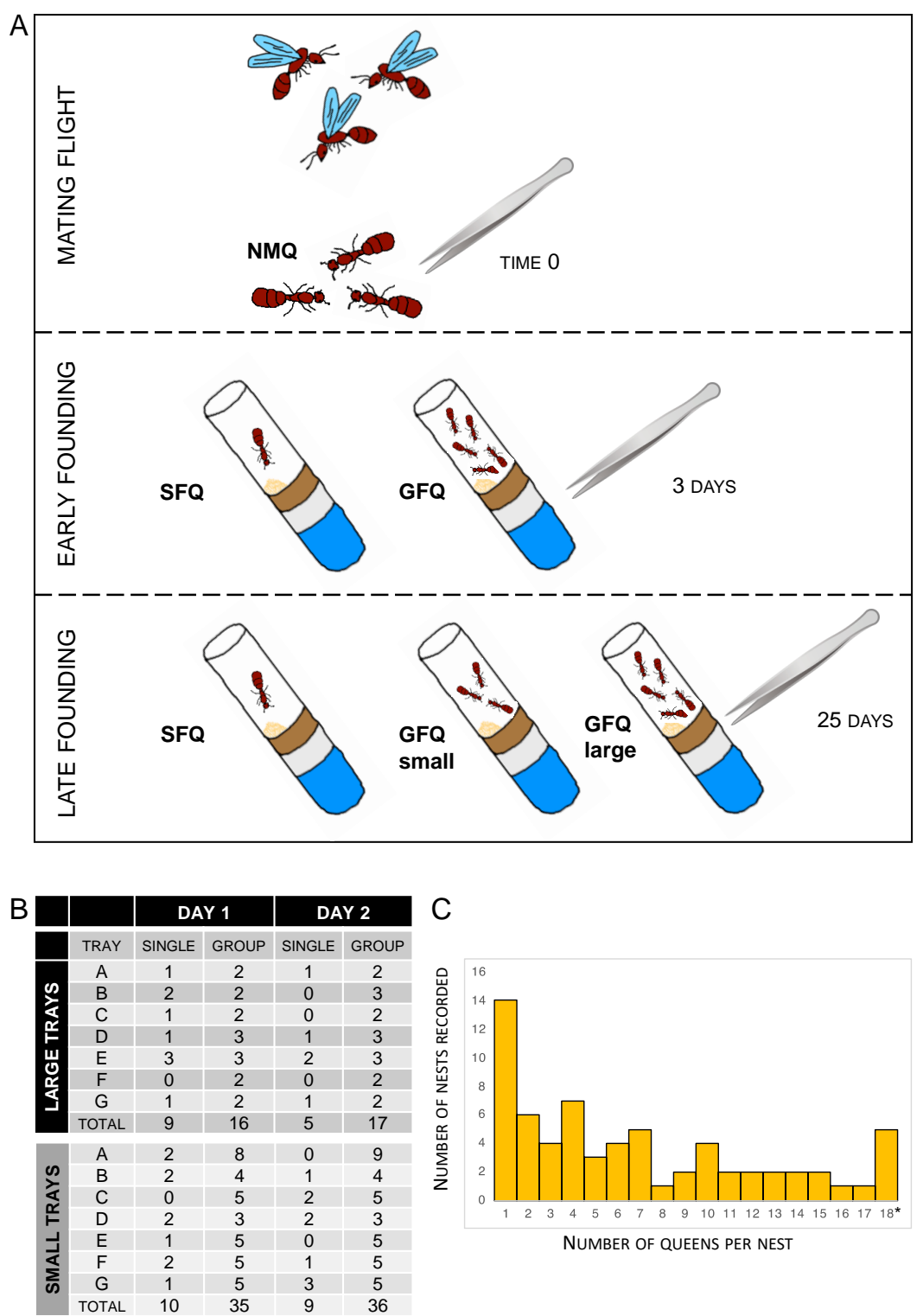
A

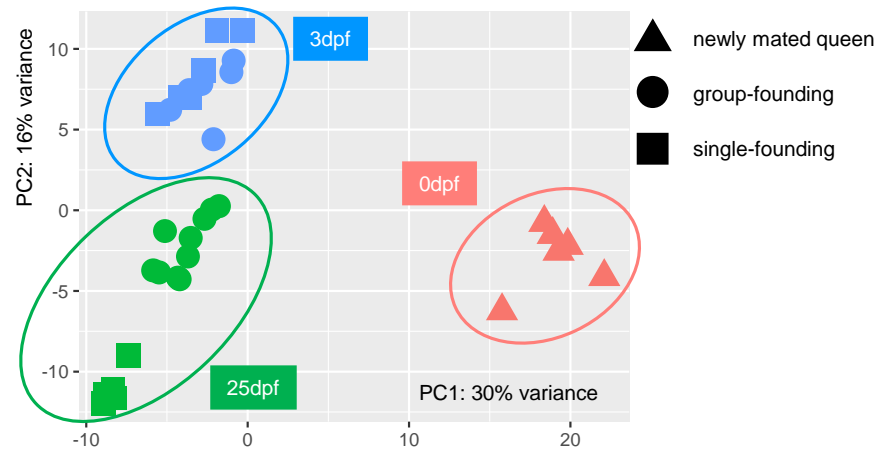

B

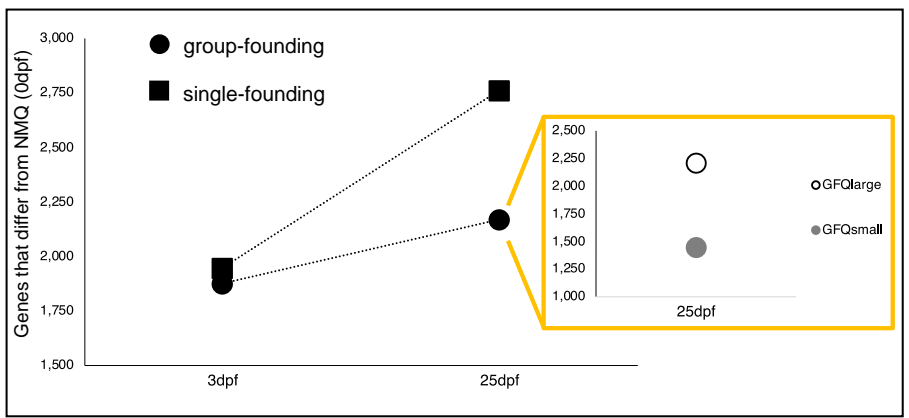

C

\begin{tabular}{|c|c|c|c|c|c|}
\hline & & DEG & $>\mid 2$-fold $\mid$ & UP & GENE ONTOLOGY / *KEGG PATHWAYS / GENE NAMES \\
\hline \multirow{3}{*}{ 흥 } & $\begin{array}{l}\text { GFQ } \\
\text { vs. NMQ }\end{array}$ & 1,874 & $\begin{array}{l}90 \\
(5 \%)\end{array}$ & $\begin{array}{l}961 \\
(51 \%)\end{array}$ & $\begin{array}{l}\text { lipid metabolic process (81), single-organism process } \\
\text { (655), transmembrane transport (77), ion homeostasis (1) }\end{array}$ \\
\hline & $\begin{array}{l}\text { SFQ } \\
\text { vs. NMQ }\end{array}$ & 1,948 & $\begin{array}{l}94 \\
(5 \%)\end{array}$ & $\begin{array}{l}990 \\
(51 \%)\end{array}$ & 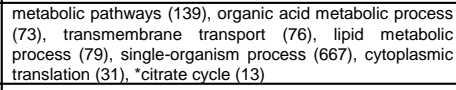 \\
\hline & $\begin{array}{l}\text { GFQ } \\
\text { vs. SFQ }\end{array}$ & 1 & 0 & 0 & Slit homolog 1 protein \\
\hline \multirow{4}{*}{ 흥 } & $\begin{array}{l}\text { GFQ } \\
\text { vs. NMQ } \\
\text { large } \\
\text { small }\end{array}$ & $\begin{array}{l}2,169 \\
2,208\end{array}$ & $\begin{array}{l}107(5 \%) \\
90(4 \%)\end{array}$ & $\begin{array}{l}1,036(48 \%) \\
1,003(45 \%) \\
694(48 \%)\end{array}$ & 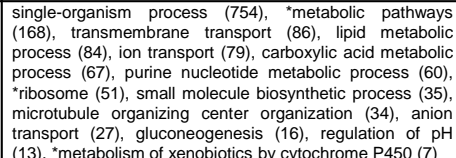 \\
\hline & $\begin{array}{l}\text { SFQ } \\
\text { vs. NMQ }\end{array}$ & 2,763 & $\begin{array}{l}136 \\
(5 \%)\end{array}$ & $\begin{array}{l}1,254 \\
(45 \%)\end{array}$ & 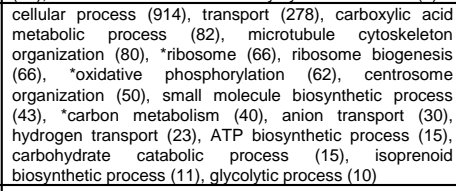 \\
\hline & $\begin{array}{l}\text { GFQ } \\
\text { vs. SFQ }\end{array}$ & 659 & $\begin{array}{c}17 \\
(3 \%)\end{array}$ & $\begin{array}{l}482 \\
(73 \%)\end{array}$ & $\begin{array}{l}\text { oxidation-reduction process (46), fatty acid metabolic } \\
\text { process (16), translation (46), centrosome duplication (14) }\end{array}$ \\
\hline & $\begin{array}{l}\text { GFQlarge } \\
\text { vs. } \\
\text { GFOsmall }\end{array}$ & 5 & 0 & 3 & $\begin{array}{l}\text { Translocase of the inner mitochondrial membrane 17b, } \\
\text { two ribosomal proteins (RpL9 and RpS30) and two } \\
\text { uncharacterized genes }\end{array}$ \\
\hline
\end{tabular}



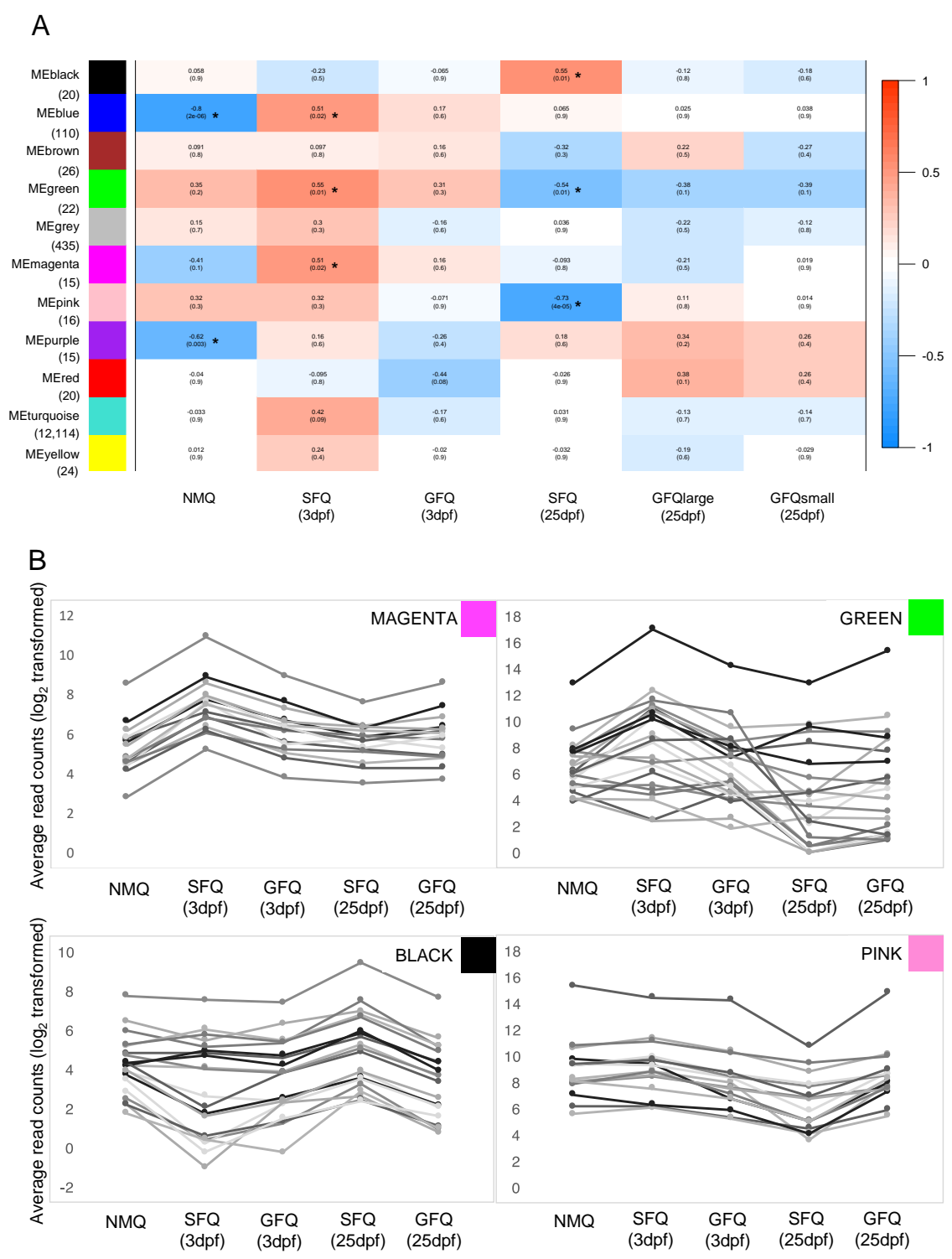

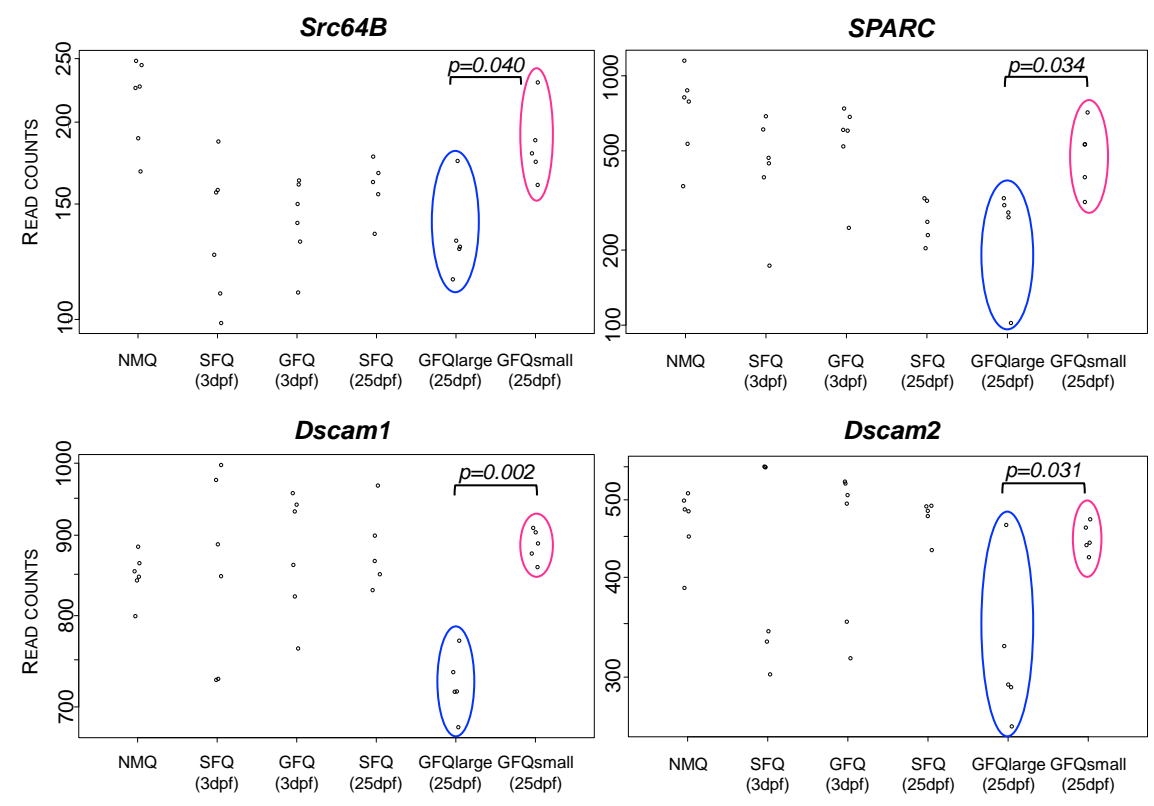